\title{
Positive response of rabbits fed varying levels of palm kernel cake as a replacement for wheat offal
}

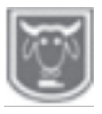

Umar, A. M. ${ }^{1}$, Muhammad, A. S. ${ }^{2}$, Adamu, N., ${ }^{1}$ and Modi, M. ${ }^{1}$ ${ }^{\prime}$ Department of Animal Production, Abubakar Tafawa Balewa University, Bauchi Abstract ${ }^{2}$ Department of Animal Science, Federal University Dutse, Jigawa State

A major cost of producing rabbits is that of feed. Palm kernel cake is cheaper and locally available than wheat offal. This study was therefore, conducted to evaluate the performance of rabbits fed Palm Kernel Cake (PKC) as a replacement for Wheat Offal (WO). Twenty weaned rabbits of both sexes were used in the experiment. The rabbits were allocated to five diets, each with four replicates. Each diet contained the same quantities of ingredients but $P K C$ and WO were varied such that diet (A) was $0 \%$ PKC and 40\% WO, (B) $10 \%$ PKC and $30 \% \mathrm{WO},(C) 20 \% \mathrm{PKC}$ and $20 \% \mathrm{WO}$, (D) $30 \% \mathrm{PKC}$ and $10 \% \mathrm{WO}$, and (E) $40 \% \mathrm{PKC}$ and $0 \%$ $W O$ to measure feed intake, growth rate and feed conversion ratio. Carcass and organs of the rabbits were analysed. Average daily feed intake of rabbits recorded for diet $A, B, C, D$ and $E$ was 49.37, 40.05, 38.18, 39.10 and 56.05. The results revealed an insignificant difference in final weights of rabbits among all treatments which ranged from $777.50 \mathrm{~g}(\mathrm{~A})$ to $965.00 \mathrm{~g}(\mathrm{E})$. The feed conversion ratio (FCR) was also not significant and ranged from $5.21-4.55$ with diet $A$ having the highest FCR. There were also no significant differences in carcass and organ weights among the treatments. The carcass weight ranged from $395.00 \mathrm{~g}$ to $594.25 \mathrm{~g}$ on diet $A$ and $E$ respectively. Diet $E$ had the highest dressing percentage (57.70\%) while the least was recorded for diet $B(53.28 \%)$. It can be concluded that $P K C$ compared favourably with $W O$ and could be used to replace the latter without deleterious effects.

Keyword: Rabbits, palm kernel cake and wheat offal

\section{Introduction}

There is a global awareness of the shortage of animal protein supply in the tropics (Adekunle and Ajani, 1999). There is also a continuous rise in the cost of production of cattle, sheep, goats, and poultry which has prompted people to explore other less common but potential sources of animal protein like rabbits. Taiwo et al., (2005) indicated several advantages of rabbit over livestock in the tropics and advocated for its increased production in Nigeria. However, as argued by Ayinde and Aromololan (1998), the cost of feeding rabbits is high and accounted for about $65.7 \%$ of the total cost of rabbit production in Nigeria. Therefore, there is a need for researchers to find cheap and readily available sources of rabbit feed in Nigeria. Rabbits, unlike poultry and swine, do not compete with man for feed stuff. The consumption and production of rabbits is also known to be without any religious taboo. Other advantages include their prolificacy, and short generation intervals. They are easy to manage because they can be fed with kitchen wastes and other agro-industrial byproducts. One of such products is palm kernel cake.

Palm kernel cake is a by-product from palm kernel industry. It is a potential nonconventional feed ingredient for animal production due to its availability and low cost (Adeshinwa, 2007). The production is not seasonal as the oil palm tree produces fruit year round. PKC is reported to have a protein content of $14-21 \%$, the fibre content of palm kernel cake (21-23\%), Dry matter of $94 \%$, Lipid content of $8-17 \%$, Ash content of 3-6\% and Gross energy values of $4,998 \mathrm{Kcal} / \mathrm{Kg}$ (Boateng et al., 2008).

On the one hand, the utilization of palm kernel cake in rabbit diets has not been extensively investigated, and on the other 


\section{Positive response of rabbits fed varying levels of palm kernel cake}

hand, the explosion of populations (Amadou et al., 2012), requires strategies to optimise cost of production. As such, harnessing the enormous opportunity by studying nutritional abilities of rabbits could not have come at a better time, since there can be no success in raising rabbits if the rabbits produced ended up being unaffordable. Therefore, investigating the use of cheaply available feed resources like PKC in feeding rabbits cannot be overemphasised. This study was carried out to determine the response of rabbits fed varying levels of palm kernel cake.

\section{Materials and methods \\ Geographical location of the experiment area}

The experiment was conducted at the rabbitry unit of Abubakar Tafawa Balewa University, Bauchi. Bauchi, a state in North Eastern part of Nigeria is located at geographical coordinates $100^{\circ} 33 \square \mathrm{N}$ and $9^{\circ} 31 \square$ E. It is bordered by seven other states: Kano and Jigawa to the North, Taraba, and Plateau to the South, Gombe and Yobe to the East and Kaduna to the West. It occupies a total area of 49,259 $01 \mathrm{sq}$ kilometers, representing about $5.3 \%$ of the total land mass of Nigeria. The state lies within the guinea savannah of the ecological zone with an annual rainfall of between $1000 \mathrm{~mm}$ and $1300 \mathrm{~mm}$ per annum. Effective rainy season starts from mid-May or sometimes early June. In contrast, the Northern part of the state starts receiving rain in late June/July. The vegetation here is not uniform, and grasses are shorter than is obtained in the Southern part of the country. The South- West region of the state is mountainous because of the affinity of the Jos-Plateau, while the Northern part is generally sandy. Relative humidity ranges from about $12 \%$ in February to about $68 \%$ in August. At the beginning of the rainy season, relative humidity is about $37 \%$
(BSADP, 1993).

\section{Experimental diets}

Twenty weaned rabbits of both sexes were used in the experiment. The animals were allocated to five diets, each with four replicates; each replicate has a rabbit kept in a separate cage. The rabbits were weighed randomly and allocated to different treatments A, B, C, D and E. Each diet contained the same quantities of maize, groundnut cake, fish meal, bone meal, salt, methionine, lysine, and premix. Other ingredients, which were however variable, are Palm Kernel Cake (PKC), and wheat offal. The PKC was used to replace (A) $0 \%$, (B) $10 \%$, (C) $20 \%$, (D) $30 \%$, and (E) $40 \%$ of wheat offal in diets $\mathrm{A}, \mathrm{B}, \mathrm{C}, \mathrm{D}$, and $\mathrm{E}$, respectively (Table 2 ).

\section{Management of experimental animals}

The experimental site is well ventilated. The feeders and drinkers were cleaned before the commencement of feeding or watering daily. The environment was also kept clean by sweeping and cleaning daily. Rabbits were weighed at the beginning of the experiment after the preliminary period of one week to determine initial weight. After that, the rabbits were weighed at a weekly interval to determine the body weight changes. Feed intake was obtained by giving $100 \mathrm{~g}$ of feed daily to the rabbits and leftovers were collected and recorded after weighing.

Carcass characteristics and organ weight analysis

At the end of the 6th week of feeding trials, two rabbits per treatment were randomly selected and slaughtered for carcass characteristics and organ weight analysis. Rabbits were starved for 12 hours before being weighed and slaughtered. Slaughtering was done by severing the jugular vein and allowing the blood to drain for five minutes. The skin was removed and the live weight, slaughter weight, carcass weight, were measured and expressed in 


\section{Umar, Muhammad, Adamu and Modi}

Table 2: Percentage composition of experimental diets

\begin{tabular}{lccccc}
\hline & \multicolumn{5}{c}{ Dietary levels of Palm Kernel Cake (\%) } \\
\cline { 2 - 6 } Ingredients & $\mathbf{0}(\mathbf{A})$ & $\mathbf{1 0}(\mathbf{B})$ & $\mathbf{2 0}(\mathbf{C})$ & $\mathbf{3 0}(\mathbf{D})$ & $\mathbf{4 0}(\mathbf{E})$ \\
\hline Maize & 45.31 & 45.31 & 45.31 & 45.31 & 45.31 \\
Groundnut Cake & 10.00 & 10.00 & 10.00 & 10.00 & 10.00 \\
Wheat Offal & 40.00 & 30.00 & 20.00 & 10.00 & 0.00 \\
Palm Kernel Cake & 0.00 & 10.00 & 20.00 & 30.00 & 40.00 \\
Fish Meal & 2.00 & 2.00 & 2.00 & 2.00 & 2.00 \\
Bone Meal & 2.00 & 2.00 & 2.00 & 2.00 & 2.00 \\
Salt & 0.25 & 0.25 & 0.25 & 0.25 & 0.25 \\
Premix & 0.24 & 0.24 & 0.24 & 0.24 & 0.24 \\
Methionine & 0.10 & 0.10 & 0.10 & 0.10 & 0.10 \\
Lysine & 0.10 & 0.10 & 0.10 & 0.10 & 0.10 \\
Total & 100.00 & 100.00 & 100.00 & 100.00 & 100.00 \\
Calculated analysis & & & & & \\
Crude Protein (\%) & 16.73 & 16.93 & 17.13 & 17.33 & 17.53 \\
Crude Fibre (\%) & 4.83 & 5.27 & 5.73 & 6.17 & 6.62 \\
Calcium & 1.00 & 1.00 & 1.00 & 1.00 & 1.00 \\
Energy (Kcal of M.E/kg) & 2157.06 & 2187.56 & 2218.06 & 2248.56 & 2279.06 \\
\hline
\end{tabular}

grams (g). The head, skin, kidney, small intestine, large intestine, heart, lungs, spleen, liver, stomach, caeca, and tail, were weighed and expressed as a percentage live weight. The dressing percentage was calculated using the mathematical formula below:

Dressing percentage $=$ carca weight $x 100$ Statistical analysis
The collected data were computed and analysed with Microsoft Office Excel (2010), and the analysis of variance as described by Steel and Torie (1980) was used in separating the means. Significant differences were separated using an alpha value of 0.05 .

\section{Result}

Response of weaned Rabbits fed Palm kernel cake as a replacement for wheat offal

Table 3: Performance of weaned Rabbits fed PKC as a replacement for Wheat offal

\begin{tabular}{|c|c|c|c|c|c|c|c|}
\hline \multirow[b]{2}{*}{ Ingredients } & \multicolumn{5}{|c|}{ Dietary levels of Palm Kernel Cake (\%) } & \multirow[b]{2}{*}{ SEM } & \multirow[b]{2}{*}{$\mathbf{L S}$} \\
\hline & 0 (A) & $10(B)$ & $20(C)$ & 30(D) & $40(E)$ & & \\
\hline Initial weight $(\mathrm{g})$ & 390.00 & 402.50 & 402.50 & 392.50 & 415.50 & 44.50 & NS \\
\hline Final weight $(\mathrm{g})$ & 777.50 & 845.00 & 862.50 & 875.50 & 965.00 & 67.65 & NS \\
\hline TWG $(\mathrm{g}$ & 387.50 & 417.50 & 460.00 & 482.50 & 550.00 & 45.09 & NS \\
\hline Daily weight gain (g) & 9.22 & 9.94 & 10.95 & 11.48 & 13.09 & 1.07 & NS \\
\hline Daily feed intake (g) & 49.37 & 40.05 & 38.18 & 39.10 & 56.05 & 7.91 & NS \\
\hline Feed conversion ratio & 5.21 & 4.38 & 3.55 & 3.54 & 4.55 & 0.92 & NS \\
\hline Feed cost $(\mathrm{N} / \mathrm{kg})$ & 29.50 & 27.02 & 25.30 & 23.50 & 21.50 & 1.76 & NS \\
\hline Feed cost (N/kg gain) & 112.73 & 97.86 & 94.32 & 96.45 & 98.90 & 5.67 & NS \\
\hline
\end{tabular}

The initial weight is presented in Table 3 showing no significant treatment effects and ranged from $390.00 \mathrm{~g}-415.50 \mathrm{~g}$. Diet $\mathrm{E}$ with $40 \%$ inclusion level of palm kernel cake had the highest initial weight $(415.50 \mathrm{~g})$. There was no significant difference on the final weight which ranged from $777.50 \mathrm{~g}-965 \mathrm{~g}$, with diet $\mathrm{E}(40 \%$ PKC) having the highest final weight $965 \mathrm{~g}$. Rabbits on all diets gained weight; however, there were no significant differences in total weight gained (TWG) 


\section{Positive response of rabbits fed varying levels of palm kernel cake}

among the dietary treatments. The TWG ranged from $387.50 \mathrm{~g}-550.00 \mathrm{~g}$. Rabbits on the diet $\mathrm{E}$ ( $40 \%$ PKC) had higher TWG than others. Furthermore, there were no significant differences in daily weight gained (DWG) among the dietary treatments. The DWG ranged from $9.22 \mathrm{~g}-$ 13.09 g. Rabbits on the diet E (40\%PKC) had higher DWG than others with $13.09 \mathrm{~g}$. There were also no significant treatment effects on the daily feed intake (DFI). The DFI ranged from $49.37 \mathrm{~g}-56.05 \mathrm{~g}$, with diet E $(40 \%$ PKC) having the highest final weight $56.05 \mathrm{~g}$. The FCR ranged from $5.21-$ 4.55 , with diet $\mathrm{A}(0 \% \mathrm{PKC})$ having the highest FCR.

Table 4: Carcass characteristics of weaned Rabbits fed P alm Kernel Cake as a replacement for Wheat offal

\begin{tabular}{lccccccc}
\hline & \multicolumn{5}{c}{ Dietary levels of Palm Kernel Cake (\%) } & & \\
\cline { 2 - 6 } Ingredients & $0(\mathrm{~A})$ & $10(\mathrm{~B})$ & $20(\mathrm{C})$ & $30(\mathrm{D})$ & $40(\mathrm{E})$ & SEM & LS \\
\hline Live weight & 710.00 & 775.00 & 850.00 & 975.00 & 1025.00 & 52.85 & $\mathrm{NS}$ \\
Slaughter weight & 675.00 & 727.50 & 800.00 & 920.00 & 967.50 & 51.02 & $\mathrm{NS}$ \\
Carcass weight & 395.50 & 412.75 & 455.40 & 560.70 & 594.75 & 41.02 & $\mathrm{NS}$ \\
Dressing \% & 55.98 & 53.28 & 53.89 & 57.34 & 57.70 & 3.00 & $\mathrm{NS}$ \\
Legs & 2.67 & 3.28 & 2.55 & 2.85 & 2.78 & 0.14 & $\mathrm{NS}$ \\
Head & 9.45 & 8.74 & 8.30 & 8.45 & 8.26 & 0.29 & $\mathrm{NS}$ \\
Kidney & 0.58 & 0.78 & 0.63 & 0.59 & 0.53 & 0.05 & $\mathrm{NS}$ \\
Small intestine & 5.68 & 5.27 & 4.28 & 5.72 & 6.63 & 1.01 & NS \\
Large intestine & 0.43 & 0.32 & 0.48 & 0.44 & 0.47 & 0.06 & NS \\
Heart & 0.17 & 0.22 & 0.21 & 0.17 & 0.17 & 0.02 & NS \\
Lungs & 0.37 & 0.44 & 0.39 & 0.59 & 0.44 & 0.06 & NS \\
Spleen & 0.05 & 0.45 & 0.3 & 0.35 & 0.35 & 0.01 & NS \\
Liver & 2.03 & 2.22 & 2.21 & 2.25 & 1.87 & 0.2 & NS \\
Stomach & 5.52 & 5.93 & 5.27 & 4.43 & 5.36 & 0.5 & NS \\
Caeca & 7.49 & 9.77 & 8.33 & 8.57 & 6.33 & 0.67 & NS \\
Tail & 0.41 & 0.50 & 0.37 & 0.47 & 0.47 & 0.02 & NS \\
Skin & 5.69 & 5.01 & 5.88 & 5.79 & 6.29 & 0.47 & NS \\
\hline S= Level of Significance; NS= Not significant; SEM= Standard Error of Means & & & &
\end{tabular}

The Live weight of rabbits presented in Table 4. There were no significant differences observed between dietary treatments in live weight. The live weight ranged from $710.00 \mathrm{~g}-1025.00 \mathrm{~g}$ with diet $\mathrm{D}(30 \% \mathrm{PKC})$ recording highest and $\operatorname{diet} \mathrm{A}$ recording the lowest. There were also no significant differences among the dietary treatments in slaughter weight which ranged from $675.00 \mathrm{~g}-967.50 \mathrm{~g}$ for diet $\mathrm{A}$ and $\mathrm{E}$ respectively. Furthermore, no significant differences were also observed among the dietary treatments in carcass weight which ranged from $395.00 \mathrm{~g}$ $594.25 \mathrm{~g}$ for $\operatorname{diet} \mathrm{A}$ and $\mathrm{E}$ respectively. Diet $\mathrm{E}(40 \% \mathrm{PKC})$ recorded the highest dressing percentage $(57.70 \%)$, followed by diet $\mathrm{D}$ $(57.34 \%)$, diet A $(55.98 \%)$, diet C $(53.89 \%)$, and diet B (53.28\%). The legs weight ranged from $2.67 \%-2.78 \%$. Diet A $(0 \%$ PKC) recorded the highest head weight and ranged from $9.45 \%-8.26 \%$. Diet C (20\% PKC) recorded the highest kidney weight among treatments which ranged from $0.58 \%-0.53 \%$. Diet D (30\% PKC) recorded the highest lungs weight among treatments which ranged from $0.37 \%$ $0.44 \%$. Diet E (40\% PKC) recorded the highest small intestine weight $(6.63 \%)$ and large intestine weights $(0.47 \%)$. On the other hand, diet B (10\% PKC) had the highest $(0.22 \%)$ heart weight while rabbits 


\section{Umar, Muhammad, Adamu and Modi}

on diet $\mathrm{A}(0 \% \mathrm{PKC})$ had the highest spleen weight. Furthermore, Diet D (30\% PKC) had the highest $(2.22 \%)$ liver weight, while the lowest (91.87\%) was recorded for diet E (40\% PKC). Diet B also recorded highest weights for stomach caeca and tail (5.93, 9.77 and 0.50 respectively) while the highest value for skin was recorded for diet C (5.88\%).

\section{Discussion \\ Performance}

The non-significant effect of PKC on final weight observed in this study agree with the findings of Aduku et al. (1988) who reported that palm kernel meal compared favourably with peanut in the diets of weaned rabbits without significant differences in the final live weight. However, Imasuen et al. (2003) reported significant effect of palm kernel meal on final live weight of weaned rabbits. Ezieshi and Olomo (2004) also reported a similar trend in broilers. The average daily feed intake did not differ significantly among the treatment means. This also confirms the report of Aduku et al. (1988); Loh et al. (2002) and Ezieshi and Olomo (2004). Also, there were no significant differences in the total weight gain, weekly weight gain, and daily weight gain between diets containing PKC and control diet. This agrees with the findings of Garcia et al. (1999) who observed a decrease in body weight gain as the palm kernel meal increases up to 40\%. Osei and Amo (1987) also reported a similar trend in broilers. There is a linear increase in the total weight gain, and the average daily weight gain as the level of PKC in the diet increases up to $40 \%$ level of inclusion, in other words, rabbits on PKC diet recorded better weight gain than rabbits on wheat offal diets. The non-significant effect of PKC in diets agree with the findings of Garcia et al. (1999), who reported that feed conversion ratio was not significantly different between the control diet and palm kernel meal based in chicks.

\section{Carcass characteristics}

For carcass analysis, the higher live weight, slaughter weight, and carcass weight of rabbits fed diet E (40\% PKM) correspond to the result on final live weight of the animals. This result on contradicts earlier reports by Garcia et al. (1999), who reported that carcass weight was reduced by additional levels of palm kernel cake in broiler diets. The dressing percentage of rabbits compared favorably with rabbits on the control diet. This contradicts the findings of Rhule (1996) who reported that dressing percentage was significantly affected by the level of palm kernel cake in the diets of pigs. The weight of other organs such as head, legs, kidney, heart, liver and spleen did not show significant differences across the dietary treatments. This does not correspond to Orunmuyi et al. (2006) result, who observed differences in liver, lungs, kidneys, and intestines.

\section{Conclusion}

The study showed that palm kernel cake can be used to replace wheat offal in diets of weaned rabbits with tremendous cost savings, especially when wheat offal is expensive and/or limited in supply. Based on the study, it is therefore recommended that palm kernel cake can be included in the diet of weaned rabbits up to $40 \%$ level of inclusion without any effect on the performance, and carcass characteristics.

\section{References}

Adekunle, O. A. and Ajani, O. I. 1999. Economics of beef marketing in Bodija market in Ibadan, Oyo State. Tropical Journal of Animal Science 1,93 - 100.

Adesehinwa, A. O. K. 2007. Utilization of Palm Kernel Cake as a Replacement 


\section{Positive response of rabbits fed varying levels of palm kernel cake}

for Maize in Diets of Growing Pigs: Effects on Performance, Serum Metabolites, Nutrient Digestibility and Cost of Feed Conversion; Bulgarian Journal of Agricultural Science 13; 593-600.

Aduku, A. O., Dim, N. I. and Aganga, A. A. 1988. Note on Comparative evaluation of palm kernel meal, Peanut meal and sunflower meal in diets for weaning rabbits. Journal of Applied Rabbit Research., 11:264-26.

Amadou, H., Dossa, L. H., \& Schlecht, E. 2012. A comparison between urban livestock production strategies in Burkina Faso, Mali and Nigeria in West Africa. Tropical Animal Health and Production, 2050, 1631-1642.

Ayinde, I.A. and Aromolaran, A.B. 1998. Economics of Rabbit in Abeokuta South Local Government Area of Ogun State.Nigerian Journal of Animal Production. 24(2:100-105.

Boateng, M., Okai, D. B., Baah, J. and Donkoh, A. 2008. Palm kernel cake extraction and utilisation in pig and poultry diets in Ghana. Livestock Research for Rural Development, 20 ( 7 ), $\quad \mathrm{R}$ e t r i e v e d f r o m http://www.lrrd.org//rrd20/7/boat200 99.htm (January 9th, 2016).

Bauchi State Agricultural Development Programme 1993. Development Statistics. BSADP, Bauchi, Nigeria.

Ezieshi, E.V. and Olomu, J.M. 2004. Comparative performance of Broiler chickens fed varying levels of palm kernel cake and maize offal. Pakistan Journal of Nutrtion, 3: 254-257.

Garcia, C.A., Gernat, A.G. and Murillo, J.G. 1999. The effect of four levels of palm kernel meal in broiler diets. CEIBA, 40: 29-295.
Imasuen, J.A., Arijeniwa A. and Otokhian, C.S.O. 2003. Evaluation of graded levels of palm kernel cake as replacement for maize in the diet of weaned Rabbits. Proceedings of the 28th Annual conference of the Nigerian Society of Animal production, I.A.R.T. Ibadan, 16th20th March.

Loh, T.C., Foo, H.L. Tan, B.K. and Jelan, Z.A. 2002. Effects of Palm Kernel cake on performance and Blood lipids in Rats. Asian-Australian Journal of Animal Science, 15: 1165-1169.

Orunmuyi, M., Bawa, G.S. Adeyinka, F.D. Daudu O.M. and Adeyinka, I.A. 2006. Effects of Graded Levels of Palm-Kernel Cake on Performance of Grower Rabbits. Pakistan Journal of Nutrition, 5 (1): 71-74.

Osei, S.A. and Awo, J. 1987. Palm kernel cake as a broiler feed ingredient. Poultry Science, 66: 1870-1873.

Rhule, S.W.A., 1996. Growth rate and carcass characteristics of pigs fed diet containing palm kernel cake. Animal Feed Science and Technology, 61: 167-172.

Steel, R.G.D. and Torrie, J.H. 1980. Principles and procedures of statistics. A biometrical approach, 2nd Edition, McGraw-Hill Book Company, New York.

Taiwo, A.A., Adejuigbe, A.D., Adebowale, E.A., Oshotan J.S. and David, O.O. 2005. Performance and nutrient digestibility of weaned rabbits fed forages supplemented with concentrate. Nigerian Journal of Animal Production. 32(1): 74-78.

Received: $16^{\text {th }}$ September, 2018 Accepted: $10^{\text {th }}$ February, 2019 